\title{
The Impact of Applied Research: Student Research as a High Impact Practice in Freshman Environmental Science
}

\author{
Billy Morris \\ Georgia Highlands College
}

\section{The Concept}

I teach environmental science at Georgia Highlands College in Rome, GA. The campus is approximately 200 acres in size and includes a 50-acre lake, 15 acres of wetlands, and two streams. It presents many opportunities for undergraduate research in environmental science, especially for nonscience majors.

In the spring of 2019 and with the support of my dean, I made plans to omit the lab manual used in Environmental Science for fall 2019 and began to acquire field supplies and testing equipment for various air, soil, water, and wildlife studies while compiling a list of campus research projects suitable for undergraduate non-science majors. My teaching goals for the course centered on utilizing student research as a high-impact practice by asking students to engage in scientific inquiry and methods rather than follow a scripted lab exercise. The schedule for the research projects included five phases: 1) identifying the question and proposing an investigation, 2) identifying lab equipment and analytical methods required, 3) establishing a sampling plan, 4) data analysis, and 5) discussion, conclusion, and campus poster session. I allowed students to work individually or in groups of no more than three. Collaboration was encouraged, and a class of 17 students produced 11 discreet research projects addressing water quality in campus watersheds, wildlife surveys, tree surveys, soil analyses, and air quality.

\section{The Process}

Managing these projects felt like overseeing a three-ring circus at times, particularly in phase one and two - identifying a research question and analytical methods required to investigate it. Each project used different equipment and techniques to sample, process, and analyze the parameters of interest, and students needed instruction and training to gain proficiency. The impossibility of managing many projects at the same time forced me to trust students to learn and practice lab skills on their own, and as each project reached a milestone of writing, analytical technique, or merely a question about how to proceed, a queue formed at my desk and the powerful effect of frequent and meaningful feedback was manifested. As we brainstormed together about ideas, techniques, and adjustments, students were motivated, curious, and willing to work toward improving writing skills, research methods, and presentation skills. They practiced critical thinking as they worked to solve problems encountered in the field, lab, and data analysis. It didn't take long for them to demonstrate to me that they were proficient in the operation of their respective analytical tools, field gear, and laboratory protocols, and we found a comfortable routine. For the next eight weeks, a combined lecture and lab once a week gave them ample time to gather their supplies, go to their respective field areas, collect data, and return to the lab for analysis and record keeping. Many students returned after regular class hours to work on their projects.

As the semester came to an end, I invited our dean of libraries to our class for a presentation on creating a poster, and in a hands-on demonstration, he led us through a critique of many poster examples and concluded with a lib-guide on best practices for creating quality presentation posters. The final phase of the student research project consisted of creating a poster that included an abstract, 
introduction, methodology, discussion, conclusion, citations, and appropriate graphics. The class peer reviewed their own rough drafts and crafted final versions over a period of two weeks. Files were uploaded to the college's poster printer queue and delivered to the class one week before presentation day. A practice poster session was held during class a few days before. On the last day of the fall semester, students set up their posters in the Student Center for two hours, where more than two hundred students, faculty, administrators, and community members circulated, talking with students and asking questions about their work. This was the first time a research-project-poster session had been held at Georgia Highlands, and the excitement and positive feedback was overwhelming.

\section{A Case Study}

One project deserves to be mentioned in particular. The work of three students took an unexpected turn and underscored the dynamic nature of research. These students were completing a $\mathrm{pH}$ comparison of lake, wetlands, and stream areas. Over six weeks, they collected dozens of samples. The students reported that they observed some high $\mathrm{pH}$ values -9 to 10 , which is toxic to most aquatic life - and had repeated the test with the same results. Furthermore, the high values were only observed from the parking lot storm drain spillway area in a small part of the lake. A comparison between rainfall events and their data spikes showed a strong correlation - that is, their high value observations occurred after rain events. They recognized that parking lot stormwater runoff was likely responsible for high values and questioned if the recent application of parking lot sealcoat was responsible for the anomalous $\mathrm{pH}$ values. They also recognized that the $\mathrm{pH}$ of sealcoat may not be the most important environmental concern; rather, it could be a proxy effect that signified other physical and chemical processes at work. They requested the safety data sheet on the sealcoat product, which revealed it was a coal-tar based product that contained significant amounts of polycyclic aromatic hydrocarbons (PAH) - compounds that are recognized by the United States Environmental Protection Administration as known carcinogens, mutagens, teratogens, as well as acute toxins in aquatic ecosystems (GemSeal Pavement Products, 2019).

As coal-tar-based sealcoat ages, it wears into small particles with high levels of PAHs that can be tracked into homes or buildings and incorporated into interior dust. For people who live adjacent to coal-tar sealcoat pavement, ingestion of PAH-contaminated house dust and soil results in an elevated potential cancer risk, particularly for young children. Exposure to PAHs, especially early in childhood, has been linked by health professionals to an increased risk of lung, skin, bladder, and respiratory cancers (Mahler et al., 2016).

As students processed this information, they realized that what began as a routine survey of water chemistry had turned into something very different. When their findings were conveyed to college administrators several things happened - public access to the lake was closed (it's widely used by the community for walking and fishing), an independent environmental testing firm was engaged to collect and sample the stormwater drain pathway and lake sediment for the presence of PAH compounds, and samples of air in campus buildings were collected for analysis of PAH compounds. Results of the tests were positive for stormwater sediment samples and negative for other areas of the lake and indoor air (Professional Environmental Management, 2020). Additional tests are planned, as students expect the particles of sealcoat fragments will eventually make their way into the lake sediment, where it can enter the aquatic food chain.

The students submitted a proposal to present their work at the National Conference on Undergraduate Research (NCUR) in Bozeman, MT in late March 2020, and were accepted. Unfortunately, the conference was cancelled due to COVID-19, but they were able to present in a virtual session held in April. During their presentation, they stated that when they began the course, they were simply looking to complete a science requirement for graduation, and the specific project 
they chose seemed to be an "easy" one. They commented on the profound effect that their routine scientific observations had brought about: campus community awareness and campus newspaper articles, the closure of public access areas, university system intervention, independent lab analyses, and environmental activism related to health and safety of humans and ecosystems. When they learned that their research was accepted for presentation at NCUR and the college had agreed to pay all expenses for the trip, I was fortunate to be with them and literally see their eyes grow wide with a fuller understanding of what had occurred as a result of their research project. Each of them told me that the most important lesson they learned is how a simple question can lead to a completely unexpected place with many more questions. To watch them experience the true nature of scientific inquiry was the highlight of my year, and is, of course, the reason we are in this business in the first place. I am fortunate to have administrative leaders who foster and encourage this type of experiential learning practice with non-STEM students. In my opinion, these students benefit the most from such practices.

\section{Conclusion}

Many lessons were learned by utilizing the high-impact practice of student research in my course, and I encourage others to consider implementing such a project into their courses as appropriate. Student participation in designing their own research projects led to increased student engagement and enhanced learning. Students who were encouraged to investigate their own interests within the learning objectives of the course were motivated, curious, and willing to work toward improving writing skills, research methods, and presentation skills. They practiced critical thinking skills as they worked to solve problems encountered in the field, lab, and data analysis. Frequent and meaningful feedback between students and the instructor ensured that students stayed on track and were accountable for making progress. A campus poster session at the conclusion of the semester allowed students to explore graphic design and develop public speaking skills.

The teaching load at two-year institutions typically doesn't allow time for our own research, let alone supervising students - it's up to faculty to find a way to utilize the time we have. With supportive leadership, existing course time can be used to make large or small changes. Give students the chance to identify something that they are interested in as it relates to course content. Let the passion you have for your discipline show - it's contagious! Keep them between the guard rails but let them wander all over the road. Be prepared for surprises and embrace new ideas and opportunities. Involve and engage your colleagues. Keep records. Most of all, show your students the joy and excitement of learning, exploring, and following the new questions.

\section{Acknowledgments}

Many thanks and much appreciation to Dr. Sarah Coakley, Dean, School of STEM, and Jason Chrisian, Division Chair of STEM, for your support and engagement during this project. You never failed to offer encouragement and positive feedback for this class as we navigated the investigations.

\section{References}

GemSeal Pavement Products. (2019). GemSeal ®Fed Spec Sealer and Fed Spec HS Sealer [Data file]. https://www.gemsealproducts.com/wp-content/uploads/2016/05/fed-spec-sds 519.pdf 
Morris

Mahler, B.J. , Woodside, M.D., \& Van Metre, P.C. (2016). Coal-tar-based pavement sealcoat - Potential concerns for human health and aquatic life. U.S Department of the Interior. http://dx.doi.org/10.3133/fs20163017

Professional Environmental Management. (2020). Sediment testing for the presence of polycyclic aromatic bydrocarbons (PAHs) in Paris Lake. [Unpublished report]. 